\title{
El intelecto agente como acto de ser personal
}

\section{The agent intellect as personal act of being}

Juan Fernando SELLÉS

(Universidad de Navarra)

Recibido: 7/02/2011

Aceptado: 15/11/2011

\section{Resumen}

En este trabajo se estudia la sugerente posición de algunos pensadores que constituyen una excepción en la historia de la filosofía respecto de la interpretación del intelecto agente, el gran hallazgo aristotélico: Francisco Canals, Leonardo Polo y sus discípulos, pues lo emplazan a nivel de "actus essendi hominis".

Palabras clave: intelecto agente, acto de ser personal, Francisco Canals, Leonardo Polo.

\section{Abstract}

In this work we study the suggestive position of some authors who constitute an exception in the history of the philosophy in respect to the interpretation of the agent intellect, the great Aristotle's discovery: Francisco Canals, Leonardo Polo and his disciples, because these authors put the agent intellect at the level of "actus essendi hominis".

Keywords: agent intellect, human act of being, Francisco Canals, Leonardo Polo. 


\section{Planteamiento}

El libro III De anima de Aristóteles es, con diferencia, la obra más comentada a lo largo de la historia de la filosofía. De este libro, el pasaje del capítulo $5^{\circ}$ en el que el Estagirita trata del intelecto agente y posible 1 es, con mucho, el más discutido de todos, y el que ha tenido interpretaciones más divergentes a lo largo de todas las épocas filosóficas. Si se acepta la distinción real tomista entre actus essendi y essentia y se reconoce en antropología, el acto de ser equivale a lo neurálgico o íntimo del hombre, lo que podríamos llamar persona o espíritu, mientras que las diversas potencias o facultades del compuesto humano conforman la esencia humana. Si esta distinción se respeta asimismo en teoría del conocimiento, el intelecto agente, por ser acto, se puede emplazar en el acto de ser humano como ser cognoscente, mientras que el intelecto posible (pasible o paciente), por ser una potencia, pertenece a la esencia humana.

Pero ésta no ha sido ni opinión común entre los pensadores que se han dedicado a la teoría del conocimiento a lo largo de todos los tiempos, ni la más secundada en la historia de la filosofía. Sin embargo, es la más acertada porque cuenta con mayor fundamentación. Para notarlo, basta recordar que, sobre el intelecto agente se pueden distinguir, en síntesis, las siguientes líneas interpretativas tradicionales por orden de antigüedad: sustancialismo, panpsiquismo humano, acto de ser, potencialismo, negación-formalismo-nominalismo y habitualismo.

1) Sustancialismo. Es el parecer de quienes asimilaron el intelecto agente a una 'sustancia separada', externa al hombre y activa respecto del conocer intelectual humano; hipótesis que admitió históricamente diversas variantes. En este grupo se pueden encuadrar los comentadores griegos clásicos de Aristóteles 2 , los árabes ${ }^{3}$ y judíos ${ }^{4}$ medieva-

\footnotetext{
${ }^{1}$ El texto dice así: "puesto que en la naturaleza toda existe por una parte un principio que es como la materia para cada género de entes y éste es el que está en potencia respecto de todas las cosas, y por otra parte existe un principio causal y activo que las produce todas como el arte por referencia a la materia, es necesario que en el alma también se den estas distinciones. De hecho, existe, por una parte, el intelecto capaz de hacerse todas las cosas, por otra, el intelecto capaz de hacerlas todas, semejante a la luz (...). Y este intelecto es separado, sin mezcla, impasible, en acto por esencia (...). El agente es superior al paciente (...). Y porque es separado es por lo que sólo es propiamente inmortal y eterno... impasible”. Aristóteles.: De Anima, 1. III, cap. 5 (Bk 430 a 10-25).

2 De este parecer fue Alejandro de Afrodisia. Cfr. mi trabajo: "La crítica tomista a la interpretación griega y neoplatónica del intelecto agente", en Intellect et imagination dans la Philosophie Médiévale, Actes du XIe Congrès International de Philosophie Médiévale de la Société Internationale pour l’Étude de la Philosophie Médiévale, Brepols, 2006, vol. III, pp. 1389-1404.

3 Sostuvieron esta opinión: Al-Kindi, Al-Farabí, Avicena, Algacel, Avempace, Ibn-Tufayl, Averroes, etc. Cfr. al respecto mis escritos: "La crítica tomista a la interpretación árabe y judía del intelecto agente”, Espíritu, LII/128, 2003, pp. 207-226; “¿Personalización o despersonalización del intelecto agente. Polo y los filósofos árabes Avicena y Averroes”, Studia Poliana, 5, 2003, pp. 147-165.

${ }^{4}$ De este cariz fueron: Isaac Israeli, Avicebrón y Maimónides. Cfr. mi aludida publicación en Espíritu, $\mathrm{LII} / 128$
} 
les, así como ciertos pensadores cristianos comprendidos entre los ss. XIII y XVII5. Como el comentador griego que inauguró este modo de pensar fue Alejandro de Afrodisia, a este movimiento se le ha llamado alejandrinismo. Ahora bien, debido a que en la Edad Media fue peculiarmente reinterpretado por Avicena, se denominó avicenis$m o^{6}$. Con todo, como el autor más representativo de esta corriente a lo largo de todos los tiempos fue -como es sabido-Averroes, a partir del s. XIII a este movimiento se le designó como averroísmo ${ }^{7}$, el cual se prolongó hasta el s. XVII, y es afín a las tesis centrales de pensadores modernos de la talla de Hegel.

2) Panpsiquismo humano. Es una interpretación inusual que hace coincidir al intelecto agente con el alma de la humanidad, una sola para todo el género humano. Se trata de la opinión de Filopón (aprox. 500-570 d. C.), un comentador griego de Aristóteles. Pero ésta hipótesis se ciñe en exclusiva a este autor y, por tanto, no ha formado escuela.

3) Acto de ser. Esta tesis intuitiva y certera debe su origen a San Alberto Magno, el cual, junto a admitir y defender ciertas tesis tradicionalmente admitidas sobre el intelecto agente ${ }^{8}$, legó un cúmulo de tesis novedosas de primera magnitud: el intelecto agente nace del orden del acto de ser humano; es un conocimiento que está-en-sí-mismo; que tendrá un conocimiento distinto tras esta vida; que puede servirse de instrumentos en su actuar (el hábito de los primeros principios). El Doctor Universalis le atribuye asimismo el deseo de saber, la libertad, la sutileza, la santidad, la profecía; y añade que es -como el espíritu- principio de individuación. Una realidad de este cariz sólo se explica porque procede de Dios 9 .

4) Potencialismo. Es la opinión de quienes afirmaron que el intelecto agente es propio de cada hombre y lo describieron como una potencia del alma humana. Para distinguirlo del entendimiento posible, una potencia pasiva, lo designaron como potencia 'acti$v a$ '. A este grupo pertenecen muchos pensadores cristianos a partir del s. XIII ${ }^{10}$. A esta tendencia se la puede denominar potencialismo, pero como el autor más destacado de

\footnotetext{
5 En el s. XIII defendieron esta hipótesis: Guillermo de Auvernia, Roger Bacon, Roger Marston, y averroístas latinos como Siger de Brabante. Cfr. mi trabajo: "Los filósofos del s. XIII que negaron el intelecto agente", Dar razón de la esperanza, Pamplona, Eunsa, 2004, 1277-1300. Entre los siglos XIV y XVI sostuvieron esta opinión: Juan de Jandún, Jacobo de Placentia y Augustino Nifo. En el s. XVII fue el parecer propio, por ejemplo, de Francisci Augustini Pallavicini.

6 Cfr. De Vaux, R.: Notes et textes sur l'Avicenisme latin aux confins des XIIeXIIIe siècle, Paris, 1934.

${ }^{7}$ Cfr. Mandonet, P.: Siger de Brabant et l'averroisme latin au XIIIe siècle, 2 vol., Louvain, 1908-1911.

8 La inmaterialidad, separación, inmortalidad, actividad abstractiva, parte del alma, potencia, inmixto, superior al posible y forma de él, impasible, unión natural, eficiente, formal con el posible, etc.

9 Cfr. mi trabajo: "Los filósofos del s. XIII que afirmaron el intelecto agente", Anuario de Estudios Medievales, CSIC, Barcelona, 38/1, 2008, pp. 445-474.

10 De este estilo fueron en el s. XIII: Juan de la Rochela, Juan Peckham y Tomás de Aquino. Cfr. al respecto mi aludido trabajo: "Los filósofos del s. XIII que afirmaron el intelecto agente". Una variante de esta opinión es la de quienes consideraron que el intelecto agente es una "virtud" del alma, o que actúa respecto del posible como la forma respecto de la materia. Cfr. mi trabajo: "El intelecto agente en los maestros franciscanos del s. XIII", Verdad y vida, 242/LXIII, 2005, pp. 127-148. En el s. XIV sostuvieron el potencialismo: Gil de Roma, R. Brito y W. Burley. En el s. XV: J. Capreolo y J. Versor, N. Tignosius, C. Landino, O. Amollinar, J. de Mechlinia, P. Niger, J. de Glogowia, S. de Ferrara y Cayetano. En el s. XVI: F. de Toledo, A. Rubio y A. Montecatini. En el s. XVII: los Conimbricenses, D. Báñez, Juan de Sto. Tomás, J. Cano y los Complutenses.
} 
este modo de pensar, y de mayor influjo posterior, fue Tomás de Aquino, a esta interpretación también se le puede designar como versión tomista.

5) Habitualismo. Es una de las tesis más fundamentadas, propia de los filósofos que consideraron al intelecto agente como un hábito ${ }^{11}$. Esta posición admitió históricamente dos vertientes: a) La de quienes asimilaron el intelecto agente a un hábito innato ${ }^{12}$. b) La de quienes lo asimilar a un hábito adquirido del posible13. El autor más representativo de la primera versión, la de hábito innato, fue -hasta donde se sabe- un comentador poco conocido de entre los ss. XV-XVI: Alfonso de Toledo ${ }^{14}$. De la segunda acepción, como hábito del posible, un ilustre defensor fue San Buenaventura15.

6) Negación-formalismo-nominalismo. Se trata un conjunto de pareceres afines propio de pensadores cristianos que, a partir del s. XIII, negaron la existencia del intelecto agente en el hombre por reducirlo a la inteligencia humana (entendimiento posible) ${ }^{16}$. Si bien el prototipo de los negadores del intellectus agens fue un autor del s. XIV, Durando, en el s. XIII Escoto sólo reconoció una 'distinción formal' entre el intelecto agente y el posible, variante a la que se puede denominar formalismo o, debido a su mentor, escotismo. Con este célebre pensador tal parecer arraigó en el escenario académico europeo con gran influjo posterior. Con todo, dado que a partir del s. XIV esta opinión se radicalizó con Ockham, se la puede llamar nominalismo, ya que éste es el nombre que se da al movimiento filosófico que legó a la filosofía posterior el Venerabilis Inceptor, y que -aunque es la menos fundada de todas- es dominante en nuestros días. Al margen de estas interpretaciones, también habría que registrar otra sobre el conocer intelectual humano que, con ningún defensor entre los comentadores aristotélicos y con pocos al margen de esa tradición hasta la Edad Moderna, pero que cuenta hoy con una nube de ellos: la del materialismo ${ }^{17}$. Sin embargo, no se puede incluir entre las anteriores, porque ignora por completo la doctrina sobre el intelecto agente.

11 Sostuvieron este parecer en el s. XIII: M. de Aquasparta y P. Hispano. Cfr. respecto del primero: Matthaei ab Aquasparta, O.F.M.: Quaestiones disputate de fide et cognitione, ed. 2a, Collegii S. Bonaventurae, Quaracchi, Florentiae, 1957, 225, 3. Cfr. respecto del segundo: Alonso, M.: Pedro Hispano, Obras Filosóficas, III, Madrid, C.S.I.C., 1952, p. 332. Entre los ss. XIV y XV quien más fundamentó este parecer fue Alfonso, arzobispo de Toledo.

12 San Buenaventura atribuyó esta opinión a los seguidores de Boecio. Cfr. San Buenaventura, In II Sent., d. 24, p. 1, a. 2, q. 4, ed. Quaracchi, vol. II, pp. 568 ss. Al primero que se suele atribuir la identificación del intelecto agente con el hábito de los primeros principios es a Temistio.

13 El mismo San Buenaventura atribuyó este parecer a Aristóteles (cfr. Ibid.), pero el Estagirita es ajeno a esta hipótesis.

14 Cfr. mi trabajo: "El intelecto agente según Alfonso, arzobispo de Toledo", Revista Española de Filosofia Medieval, 16, 2009, pp. 95-121.

15 Cfr. San Buenaventura, In II Sent., d. 24, p. 1, a. 2, q. 4, ed. Quaracchi, vol. II, pp. 568 ss.

16 De este parecer, en el s. XIII, fueron: Roberto Grosseteste, D. Escoto, P.J. Olivi, Gonzalo de España. Cfr. mi aludido trabajo: "Los filósofos del s. XIII que negaron el intelecto agente". En el s. XIV sostuvieron esta opinión: R. Llull, G. de Ockham, J. de Buridán, N. Orestes y B. Pelacani. Entre los siglos XV y XVI: N. de Ámsterdam y F. Melanchton. En el s. XVII: M. Villaverde, F. de Oviedo, J. de Lugo, D. Blasco, J. Castellui, F. Peynado, H. Cavellum, F. Suárez, G. Vázquez, J. Merinero, A. de Sonneno, I. Ambrosino, I. de Oddo, B. Mastri y B. Belluti.

17 Se trata de ese parecer en el que se puede englobar el materialismo, fisicalismo, corporalismo, empirismo, sensismo, neurologismo, etc., es decir, la opinión que, en el fondo, reduce el intelecto agente a 
Averroes, San Alberto Magno, Sto. Tomás de Aquino, San Buenaventura, Escoto y Ockham. Como se advierte, las diversas líneas hermenéuticas siguen (salvo la singularidad de Filopón) a famosos filósofos de la historia del pensamiento occidental (la mayoría pertenecientes al s. XIII) ${ }^{18}$. Seguidamente se investigará la versión del intelecto agente que, con escasos defensores, es la más sugerente y que, pudiendo recabar apoyatura en los escritos de San Alberto Magno, está insinuada en algunas obras de Francisco Canals, y es explícita en las de Leonardo Polo. Esta tesis ha sido continuada en la actualidad por los discípulos de ambos, pero lamentablemente es poco conocida.

\section{El intelecto agente según Francisco Canals Vidal (1922-2009)}

Este pensador catalán de formación netamente tomista dispone de dos trabajos interesantes respecto de este tema: El lumen intellectus agentis y Sobre la esencia del conocimiento. Pasemos a resumir sus claves.

a) En 1956 publicó un artículo titulado "El "lumen intellectus agentis""19, que posteriormente sería republicado sin variaciones en otras dos ocasiones: una, en su libro Para una Fundamentación de la metafísica (1968) ${ }^{20}$, y otra en Cuestiones de Fundamentación (1981)21, lo cual denota que es un texto nuclear o muy querido por el autor, así como un tema no sometido por él a cambios, al menos durante los 25 años que median entre dichas publicaciones. En el interior del artículo Canals advierte que la clave del arco noético tomista es el intellectus agens ${ }^{22}$; que esta doctrina paso inadvertida por el lenguaje de cuño fisicalista ('causa eficiente' del conocer) usado en su descripción ${ }^{23}$. Pero dejando al margen los modos de decir, Tomás de Aquino sabe -afirma Canals- que "el alma intelectiva humana tiene por su esencia, no sólo la potencia o capacidad intelectual, sino también la virtud activa que

la inteligencia, admitiendo para ella un soporte orgánico, neuronal, que muere con él. Aunque este materialismo cuenta con algunos defensores en la antigüedad clásica (Demócrito, Epicúreo, Diógenes, Estratón de Lámpsaco, etc.) y con algunos modernos (Hobbes, Hume, etc.), es un fenómeno relativamente reciente (Feuerbach, Marx -y por lo general los neomarxistas-, Comte, Nietzsche, Freud, Neurath, Carnap, Ryle, Austin, Russell, Quine, -y buena parte de los filósofos analíticos-, algunos defensores del evolucionismo, ciertos filósofos postmodernos, etc.). Pero ha sido la opinión minoritaria en la historia de la filosofía, y desde luego, la menos fundamentada por sus representantes.

18 No todas estas tesis han perdurado de igual modo en el tiempo. Las más longevas ha sido el sustancialismo (19 siglos) y el habitualismo (18 siglos) seguidas de las restantes (acto de ser, potencialismo y formalismo-nominalismo) que, aparecidas en el s. XIII, llegan hasta hoy.

19 Cfr. Canals, F.: "El 'lumen intellectus agentis'”, Convivium, 1, 1956, pp. 101-136.

20 Canals, F.: Para una Fundamentación de la metafísica, Barcelona, Cristiandad, 1968.

21 Canals, F.: Cuestiones de Fundamentación, Universidad de Barcelona, 1981, cap. I, pp. 11-40.

22 Cfr. Canals, F.: “El 'lumen intellectus agentis"”, Convivium, 1, 1956, p. 102.

${ }^{23}$ Cfr. Ibid., p.103. 
hace todas las cosas 'in esse intelligibili' proporcionado a ella. En consecuencia, sólo impropiamente se caracteriza al intelecto agente cuando se dice que es una 'potencia' o 'facultad' distinta del entendimiento posible; debe decirse, en realidad, que es una 'virtus' causativa o factiva (que, según Aristóteles, 'por su esencia es acto'), que se refiere al entendimiento posible como el 'acto' a la 'potencia'"24.

Canals afirma que, para el de Aquino, el intelecto agente es connatural a la mente humana, la cual, careciendo de los inteligibles en acto (intelecto posible), posee en sí connaturalmente el acto de los inteligibles (intelecto agente). A continuación, y tomando pie de la tesis de Báñez "esse est actualitas omnis formae vel naturae" (In Iam., 1. 3, a. 4), añade que los diversos grados de entes (vivientes, intelectuales, etc.) se miden por los diversos grados de 'esse'. Así, si vivir es cierto ser perfecto, el conocer no se añade a la vida como algo extrínseco. Por tanto -como afirmó Cayetano- "intelligere nihil aliud est quam quoddam esse" (In De Anima, 1. III, c. 5). Lo que precede indica, para Francisco Canals, que, si bien en el hombre hay diversos modos de conocer que son accidentes suyos (la operación inmanente -afirma- es una cualidad, una realidad predicamental), con todo, como el 'esse' del 'intelligere' es el remedio a la imperfección de la realidad creada, pues por el conocer se vence la finitud ('anima quodammodo omnia'), "en definitiva: en la escala de los seres la intelectualidad no es nunca un 'accidente' o capacidad sobrevenida a la naturaleza del sujeto intelectual... sino la aptitud para recibir y la ordenación a poseer, como desarrollo y enriquecimiento de su ser, la actualidad inteligible" 25 .

Ahora bien, que el conocer sea una 'aptitud para recibir' no indica que sea un acto, sino más bien una potencia. Por tanto, desde este planteamiento no se puede concluir que la raíz del conocer humano sea del orden del actus essendi. Por otra parte admite que "la tesis de que la inmaterialidad constituye la intelectualidad, implica en definitiva: $1^{\circ}$ ) :a enérgica reducción del 'intelligere' en cuanto tal al orden del 'esse' como acto y perfección, de suyo infinitos, del 'ente'. $2^{\circ}$ ) La caracterización de la naturaleza intelectual como la constitutiva aptitud del 'ente' inmaterial para aquella más alta participación del 'esse', que es justamente el 'intellige$r e$ '. En otras palabras: la naturaleza intelectual no es sino la naturaleza infinita del ente al participar el 'esse' con independencia de la materia"26. Pero con esta descripción, lo intelectual humano está todavía en el orden de la 'aptitud' o 'potentia ad esse', no en el 'esse'. Por tanto, de acuerdo con esta propuesta de Canals todavía no podemos emplazar al intelecto agente en el actus esse hominis.

Además, Tomás de Aquino afirmó la existencia una distinción real entre el 'esse' y el 'intelligere' de todo espíritu creado (cfr. S. Th., I, q. 54, a. 2, ad 2), pues el ser y el entender sólo se identifican en el Acto Puro. Pero también admitió que

\footnotetext{
24 Ibid., p. 107. Cita el texto tomista de $S$. Th., I, q. 87, a. 1, ad 2

25 Ibid., p. 116.

26 Ibid., p. 117.
} 
"in hoc quod cogitat aliquid, percipit se esse", es decir, que el propio ser no es ajeno al conocer en las criaturas intelectuales. De lo cual Canals concluye que "la actualidad connatural del entendimiento... radica en su misma subsistencia y 'posesión en si' del 'esse"'27, es decir, la intelección no es algo sobreañadido a tales seres, sino una perfección de su ser inmaterial. Con todo, cabe preguntar si tal perfección coincide completamente con su ser o se distingue realmente de él. Para explicarlo, Canals retoma la frase del Aquinate según la cual "omne quod manifestatur, lumen est', y con ella explica que el conocer se asemeja a la luz en cuanto que manifiesta la verdad, y ésta, al ser. Con sus palabras: "el acto y luminosidad intelectual que hemos llamado 'luz' no es sino el acto y comunicabilidad del 'esse" 28.

Sentado lo que precede, El Profesor Canals -en las últimas páginas de su trabajo- centra la atención en la estructura de la mente humana: "in intelligentiis distinguitur potentia et actus... Et hoc completur in anima humana" (De ente et essentia, c. 5). El alma humana, por el intelecto posible, es potencial respecto de los inteligibles abstraídos de los sentidos, pero es activa respecto de ellos por medio del intelecto agente. "El entendimiento agente... es la misma luz del alma"29. Esto indica que la mente está compuesta de potencia y acto. Por tanto, no solo es inteligible, sino también inteligente. Además, sabe que es intelectiva, no porque ese conocer suyo sea su ser, sino un hábito mediante el cual el alma se conoce. Con todo, ese hábito no es un 'accidente' del alma, sino que forma parte de su realidad 'sustancial'. El autor mantiene, por tanto, la distinción real entre el esse hominis y el hábito intelectual que alcanza a conocerlo. Según él, ese hábito se activa "en la iluminación que hace los inteligibles en acto, por los que el hombre entiende"30, es decir, simultáneamente a la acción del intellectus agens. Queda, en consecuencia, por exponer la índole del intelecto agente, sobre el que al final de su trabajo se pronuncia en estos términos: "al 'esse', que, 'en cuanto es del alma, no depende del cuerpo, le compete la luz inteligible que llamamos "entendimiento agente"'31. Según esto, parece que para Canals el intelecto agente pertenece al esse hominis sin ser idéntico a él; es decir, es la luz radicada en lo más íntimo del hombre si identificarse enteramente con la intimidad.

b) Su trabajo Sobre la esencia del conocimiento 32 es 31 años posterior al precedente artículo. Su capítulo I lleva el sugerente título "El conocimiento como acto y ser del ente cognoscente”. Ya no está ceñido - como el anterior- al comentario de

\footnotetext{
27 Ibid., p. 124.

28 Ibid., p. 127.

${ }^{29}$ Ibid., p. 130.

30 Ibid., p. 133.

31 Ibid., p. 135.

32 Canals, F.: Sobre la esencia del conocimiento, Barcelona, Promociones Publicaciones Universitarias, 1987, pp. 279-309.
} 
los textos del Aquinate, aunque no falten referencias al corpus tomista. Parte notando que el conocimiento humano es una realidad de experiencia inmediata que, en su primer horizonte se patentiza como posesión intencional de otras cosas a la par que tiene cierto conocimiento de sí propio. Sigue afirmando que el conocer humano es susceptible de explicar las cosas naturales, pero él mismo no es explicable desde ellas: "toda explicación de qué sea el conocer que se mueve en el horizonte de las relaciones surgidas entre las cosas por la interacción fundada en sus cualidades naturales y actividades propias, es incapaz de alcanzar a pensar qué sea propiamente conocer; porque en el fondo no se ha situado en el fondo de la experiencia del conocimiento" 33 .

Al exponer la sentencia aristotélica "el sentido en acto es lo sentido en acto", Canals explica la unidad entre conocer y conocido. Conocer sensiblemente y lo sensible conocido son dos dimensiones de índole heterogénea que se hacen una al conocer. De modo semejante, "el entendimiento en acto es lo entendido en acto", o sea, son uno. Explica que el conocer de la inteligencia añade al de la sensibilidad que posee la forma sin las condiciones de la materia; que, por medio del conocer (sensible e intelectual), el alma humana es capaz de hacerse todas las cosas, y, al conocerlas, algo notamos acerca de cómo es nuestro conocer, pues somos conscientes de que se nos muestra "como una actividad implantada en la naturaleza del viviente humano y emanando de ella" 34 . Seguidamente pasa a exponer lo que denomina "la infinitud del conocer en cuanto acto", expresión a mi modo de ver imprecisa, pues nuestro conocer no es 'infinito en acto', sino 'en potencia'; o sea, se puede decir que es 'operativamente infinito' en cuanto que puede ejercer una operatividad sucesiva y sin coto, pero no es infinito en acto, sino en potencia. En efecto, en él no cabe una operación última, pero eso no significa que su operatividad sea infinita en acto. Con todo, al margen de esta cláusula, lo que intenta Canals es fijar la atención, más que en el acto de conocer, en el entendimiento 'en cuanto cognoscente', es decir, buscar la índole del conocimiento mismo. Para ello, vuelve a tomar apoyatura en la tesis de Cayetano según la cual "sentir y entender no son sino cierto ser" (In III De Anima, c. 5). Lo que precede indica que para comprender el conocer hay que ponerlo en la línea del 'esse' o del acto, no en la de la 'essentia' o potencia. En este sentido podría afirmarse que... el conocer en sí mismo y en cuanto tal es propiamente infinito"35, pues, como es sabido, lo que limita al ser en los entes es la esencia. Como se puede apreciar, este trabajo emplaza de modo más explícito que el anterior al intellectus agens en el orden del esse hominis.

Titula el último epígrafe de este trabajo "el conocer como ser y acto del cognoscente en cuanto cognoscente". En él se lee que "la universalidad cognoscitiva del

\footnotetext{
33 Ibid., p. 282.

34 Ibid., p. 296.

35 Ibid., pp. 304-5.
} 
alma tiene de modo originario y directo el significado de la constatación de lo que el conocer es en cuanto conocimiento"36, es decir, sabemos que la interioridad de nuestro conocer está infinitamente abierta a lo que es. Con todo, no aparece aquí referencia explícita alguna al intelecto agente. Las tesis de Canals las veremos más perfiladas en Leonardo Polo, y también su lenguaje expositivo, que ya no será 'ontológico' sino 'antropológico'. Polo conoció a Canals, pero nunca hablaron de este tema. Pese a que la inicial publicación de Canals es anterior a las de Polo, éste no tuvo influjo de Canals en este punto.

\section{El intellectus ut actus según Leonardo Polo (1926-)}

Este filósofo madrileño es el autor que más explícitamente ha colocado el intelecto agente a nivel de acto de ser personal humano ${ }^{37}$. Aunque en su extensa obra haya cierta evolución al respecto, su tesis última es que el intelecto agente es el conocer personal o conocer a nivel de acto de ser. Demos un repaso a su tratamiento de este tema a lo largo de su producción entera.

A. Denominaciones y revisión histórica. Por lo que respecta a los nombres, Leonardo Polo llama de diversas formas al intelecto agente. En sus escritos iniciales lo designaba, o bien como "intelecto agente", o bien como "núcleo del saber"38, entendiendo por tal lo más radical del conocer humano. Por otra parte, en la mayor parte de sus escritos posteriores, sobre todo los referidos a teoría del conocimiento, habla de él según la denominación aristotélica clásica de "intelecto agente"; y sólo en sus publicaciones últimas, especialmente en los trabajos de antropología, lo designa con los nombres "intellectus ut actus"39 o "intellectus ut co-actus" 40 , "lumen intellectus" 41 o "intelecto personal" 42.

En cuanto a las fases interpretativas del intelecto agente habidas a lo largo de la historia de la filosofía, Polo distingue las siguientes: a) El hallazgo aristotélico. b) Las hipótesis sustancialistas neoplatónicas, árabes, judías y averroístas latinas, que

\footnotetext{
36 Ibid., p. 306.

37 Cfr. mi trabajo: El conocer personal. Estudio del entendimiento agente según Leonardo Polo, Cuadernos de Anuario Filosófico, Serie Universitaria, $n^{\circ}$ 163, Pamplona, Servicio de Publicaciones de la Universidad de Navarra, 2001.

38 Cfr. Polo, L.: El acceso al ser, Pamplona, Eunsa, 2004, pp. 29, 54, 114, 137, etc.

39 Cfr. Polo, L.: Antropología trascendental, I, Pamplona, Eunsa, 2003, p. 153. Nominalismo, idealismo y realismo, Pamplona, Eunsa, 2001, p. 237. "El intellectus ut actus, lo que Aristóteles llama intelecto agente, es un trascendental personal, que se convierte con la libertad trascendental. En este sentido, es mejor llamarlo intellectus ut co-actus, o también núcleo del saber. Como se ha dicho, la antropología es una ampliación de los trascendentales". Antropología, I, ed. cit., p. 119, nota 120.

40 Cfr. Antropología, I, ed. cit., 119; Ibid., II, p. 103, nota 24.

${ }^{41}$ Cfr. Antropología, I, ed. cit., p. 157.

42 Cfr. Antropología, I, ed. cit.,pp. 212 ss; Ibid., II, p. 6.
} 
considera erróneas. c) La interpretación potencialista, es decir, tomista, con la que no está de acuerdo. d) Las versiones formalista (Escoto) y nominalista (Ockham), que juzga equivocadas. e) La opinión habitualista que lo identifica con el hábito innato de los primeros principios, que no comparte. f) La pérdida de este hallazgo en la filosofía moderna y contemporánea, olvido que le parece deplorable. Explicitemos brevemente su concepción de estos periodos:

a) El descubrimiento aristotélico del intelecto agente le parece a Polo un hallazgo de primera magnitud, sobre todo, porque este intelecto es una realidad humana superior al alma ${ }^{43}$. Polo distingue realmente entre 'alma' y 'espíritu' o persona, e indica que el intelecto agente es personal ${ }^{44}$, o si se quiere, es el acto de ser personal humano visto como ser cognoscente; de otro modo: la luz radical que la persona misma es. Por tanto, lo que Aristóteles llama intelecto agente hay que reducirlo -según Polo- a la persona, al acto radical. Es la consideración del esse humano en cuanto intelección.

b) La interpretación del intelecto agente como sustancia separada es -para Polo- una extrapolación debida a entender el acto como 'sustancia' (entelécheia), no como acto cognoscitivo (enérgeia) ${ }^{45}$. Los representantes más célebres de esta interpretación sustancialista fueron, según él, Avicena y Averroes ${ }^{46}$, pero sus divulgadores europeos fueron los averroístas latinos ${ }^{47}$. Su crítica a estas versiones radica, en suma, en que el criterio de separación de las sustancias no se debe confundir con la separación propia del conocer 48 . Ni el intelecto agente es una sustancia separada, ni es la sustancia del sujeto humano, porque éste no es una 'sustancia'49; tampoco un accidente. Es, más bien, una característica radical de la persona. La noción de persona indica apertura, relación constitutiva a otra persona. En cambio, no tienen ese significado las categorías de 'sustancia' y 'accidentes'. Por eso Polo indica “que es conveniente elevar el lumen intellectus hasta el nivel de la persona. Con ello se deja de lado el sustancialismo"50.

\footnotetext{
43 Cfr. Curso de teoría del conocimiento, II, Pamplona, Eunsa, 1998, $3^{\text {a }}$ ed., p. 133; Curso de psicología general, Pamplona, Eunsa, 2009, p. 46. "La consideración primaria de la voluntad permite distinguirla de la inteligencia, otra potencia espiritual cuyo antecedente es el intelecto agente. Extremando la distinción, sostengo que la inteligencia deriva, según un hábito, del ser humano; mientras que la voluntad se confina en el alma". La voluntad y sus actos, I, Pamplona, Servicio de Publicaciones, 1998 , p. 35.

44 "No es aceptable, tanto porque el intelecto agente no es personal -ya que el estagirita desconoce el carácter personal del hombre- como porque de ese modo no se atiende a la ampliación de los trascendentales". Antropología, I, ed. cit., p. 225.

45 Cfr. Curso de psicología general, ed. cit., p. 344.

${ }^{46}$ Cfr. Sobre la existencia cristiana, Pamplona, Eunsa, 1996, p. 98.

47 Cfr. Curso de teoría del conocimiento, II, $3^{\text {a }}$ ed., p. 156; Ibid., III, 1999, $2^{\text {a }}$ ed., p. 12.

48 Cfr. Curso de teoría del conocimiento, I, 1987, $2^{\mathrm{a}}$ ed., p. 111.

${ }^{49}$ Cfr. Curso de teoría del conocimiento, I, ed. cit., p. 114.

50 Antropología, I, ed. cit., p. 157.
} 
c) En cuanto al potencialismo, del estilo de Tomás de Aquino51, Polo afirma que "el intelecto agente no es una potencia formal" 52 , puesto que es acto, pero no como "operación inmanente', o como 'hábito' (adquirido o innato), sino como acto de ser: "se puede poner en el orden del esse, a partir de la distinción real entre esencia y ser: no es ni facultad ni sustancia, porque el esse hominis tampoco lo es... Si el intelecto agente está en el orden del esse hominis y admitimos la distinción real, el intelecto agente no puede ser más humano: pertenece al orden personal"53.

d) Tampoco acepta la versión escotista -el formalismo- por varios motivos: porque Escoto no admite la distinción real entre essentia-actus essendi en el hombre, ya que sostiene la simplicidad del alma humana y su indistinción de las potencias; porque tiene una "interpretación causalista del entendimiento agente" 54 , etc. En menor medida está de acuerdo con el nominalismo ockhamista, que sólo acepta una distinción de nombres entre el intelecto agente y posible.

e) Respecto del habitualismo, Polo señala que el intelecto agente se distingue de un hábito innato, en especial del de los primeros principios: "el núcleo del saber (intelecto agente) no es el intelecto, entendido como hábito de los primeros principios" 55 , porque tal hábito tiene como tema los primeros principios, pero a ninguno de ellos los conoce como personas. En cambio, si el intelecto agente es de índole personal, su tema no puede ser sino personal.

f) En cuanto a la modernidad filosófica, Polo escribe que "en la filosofía moderna esta noción se pierde, ya sea por el prejuicio intuicionista (voluntarismo subjetivista), o por el innatismo (objetivismo), pues si nuestra inteligencia es intuitiva, no necesita de intelecto agente... Si nuestra inteligencia tiene las formas de antemano, no según la operación, sino según su propia constitución ontológica, tampoco necesita del intelecto agente"56. La filosofía moderna olvida el descubrimiento cristiano del concepto de persona y su radicalidad, y con él, el de intelecto agente, pasándose a hablar únicamente de la inteligencia o razón, viendo a ésta como una "potencia" cognoscitiva. Por lo demás, no es conveniente -según Polo- confundir la realidad del intelecto agente con otras instancias postuladas por pensadores modernos. Por ejemplo, "el núcleo (del saber o intelecto agente) no es lo ignoto (la x kantiana), puesto que lo ignoto se supone, sino que el conocimiento depende en exclusiva del núcleo"57. Asimismo, "Hegel interpreta el intelecto agente aristotélico de acuerdo con su pretensión de identificar la razón humana con la divina. El intelecto agente para Hegel es afín a la nóesis noéseos. Esta lectura de

\footnotetext{
51 "Tomás de Aquino, al tratar de dirimir las dificultades que conlleva la noción de intelecto agente único, entiende incluso al intelecto agente como una facultad del alma". Antropología, I, ed. cit., p. 156. 52 Curso de teoría del conocimiento, I, ed. cit., p. 234. Ibid., II, ed. cit., p. 178; Ibid., p. 235.

53 Curso de teoría del conocimiento, III, Pamplona, Eunsa, 1999, 2a ed., p. 12.

54 El acceso al ser, ed. cit., pp. 212-213. Y añade: "El carácter productor del intelecto hay que entenderlo en términos teóricos, es decir, como iluminación o constitución del inteligible en acto. Así pues, también cabe decir que en Aristóteles está presente claramente la producción, pero, asimismo, es claro que en Aristóteles la producción está pensada en un nivel teórico". Ibid.

55 Nominalismo, idealismo y realismo, ed. cit., p. 150.

${ }^{56}$ El acceso al ser, ed. cit., p. 56.

57 Curso de teoría del conocimiento, II, ed. cit., p. 156.
} 
Aristóteles no es correcta" 58 , sino un averroísmo de cuño hegeliano. Polo repara que la pérdida de esta realidad noética recorre en buena medida -salvo excepciones como Brentano- la filosofía contemporánea. Así, por ejemplo, "Heidegger confesó, sobre todo al final de su vida, que la noción de intelecto agente es fundamental y que una investigación acerca de ella podría enderezar la ontología por caminos sumamente prometedores. Pero en Ser y tiempo el intelecto agente no es tenido en cuenta"59.

B. la indole del intelecto agente. Como se ha adelantado, para Polo, el intelecto agente forma parte del acto de ser del hombre60, el acto 'primario' en el hombre, no el acto de ser como 'primer principio', puesto que la persona humana no es un primer principio 61 . En efecto, los primeros principios son el fundamento de la realidad, pero el intelecto agente no fundamenta nada, porque el conocer es una denominación extrínseca para las cosas. Por eso, "la persona no es la sustancia clásica ni el sujeto de la filosofía moderna. El intelecto agente tampoco es una cosa ni la otra"62. E1 intelecto agente es acto, "el acto de los inteligibles en acto"63, pero acto como acto de ser personal, no como acto de ser principial, fundante y extramental. Ahora bien, el acto de ser personal es superior al que no es persona. Las notas distintivas del acto de ser personal son -según Polo- la coexistencia libre, el conocer y el amar personales. El intelecto agente equivale a uno de esos radicales, el conocer personal, que no existe desvinculado de los demás. En suma, lo que precede indica que "el intellectus ut co-actus no es un único acto"64, o también, que el acto de ser personal humano no es simple (simple, sólo es Dios). Somos una persona, pero el acto de ser que la conforma admite composición, pues el amar personal, por superior, es irreductible al conocer personal, y éste, a su vez, a la coexistencia libre personal. Dicho de otro modo: el acto de ser humano es co-acto de ser.

C. La función del intelecto agente. En cuanto al oficio del intelecto agente, Polo niega que su papel se reduzca a iluminar los fantasmas 65 , porque de ser así, su tarea

58 El acceso al ser, ed. cit., p. 114.

59 Curso de teoría del conocimiento, II, ed. cit., p. 156.

60 Hegel y el posthegelianismo, Pamplona, Eunsa, 1999, $2^{\text {a }}$ ed., p. 310.

61 "El intelecto agente es el acto intelectual radical o personal". Curso de teoría, IV/2, Pamplona, Eunsa, 1994, 141. "Estimo que el intelecto agente... como acto donal es un trascendental personal. Como acto de los inteligibles actuales, es superior a lo inteligible actual. Como iluminador de lo intelectual, es superior a lo que ilumina y a la iluminación (la iluminación es el hábito)... El carácter donal, personal, del acto intelectual radical del hombre, da razón de lo que los filósofos modernos llaman sujeto y es superior a la interpretación reflexiva del pensar". Ibid., p. 143.

62 "El núcleo del saber no es el principio trascendental. Justamente conviene llamar principio a aquello de que primariamente se distingue el núcleo del saber en el plano trascendental. El principio trascendental es el ser". El acceso al ser, ed. cit., p. 54.

63 Curso de teoría del conocimiento, I, $2^{\mathrm{a}}$ ed., p. 234.

${ }^{64}$ En el Curso de teoría del conocimiento, II, se repite muchas veces esta expresión. Cfr. $3^{\mathrm{a}}$ ed., pp. $158,170,204,225,232,233,236$, etc.

65 Antropología, I , ed. cit., p. 180. 
sería coadyuvante $\mathrm{y}$, en consecuencia, un conocer carente de tema propio66. Efectivamente, Polo advierte que dicha iluminación no puede reducirse a iluminar las especies de la sensibilidad intermedia, pues debe acompañar al intelecto posible en todo su recorrido, es decir, en toda su activación, ya sea a modo de operaciones inmanentes o de hábitos adquiridos ${ }^{67}$. Interpreta los hábitos de la inteligencia como el perfeccionamiento intrínseco de esta facultad, pues con ellos crece como inteligencia ${ }^{68} \mathrm{y}$, por tanto, las operaciones inmanentes que ejerce tras la adquisición de los hábitos son más cognoscitivas que las precedentes69. Así "cambia también la relación del intelecto agente con la inteligencia como potencia... La nueva formulación de la noción de intelecto agente acentúa la importancia de la noción de hábito. El hábito como perfeccionamiento de la facultad por la posesión intrínseca de su operación (no del télos de su operación: el objeto es poseído sólo por la operación), se debe a la iluminación del intelecto agente (lo poseído intrínsecamente por la facultad es la operación iluminada). La inteligencia así entendida es una facultad

66 La libertad trascendental, Pamplona, Eunsa, 2005, p. 89.

67 "Si los hábitos son... actos y correlativamente perfecciones de la facultad, entonces los hábitos tienen que ser iluminaciones de las operaciones por el intelecto agente cuando se trata de hábitos intelectuales... De ahí derivan los hábitos, y no causalmente, sino de acuerdo con la índole del intelecto. El intelecto es la luz, y esto no es metafórico porque el intelecto es más luz que la luz física". La libertad trascendental, ed. cit., 89. Y en otra parte añade: "El intelecto agente es más de lo que dice Aristóteles (no es lo que dice Aristóteles), quien no ha visto su valor iluminante de actos y, por tanto, no lo ha puesto en relación con el conocimiento habitual. Y como estimo que hay que hacerlo, lo formulo axiomáticamente: el conocimiento habitual es debido al intelecto agente. El axioma de los hábitos dice que la inteligencia es susceptible de hábitos; ahora se añade: los hábitos son posibles por el intelecto agente. Así se completa la formulación del axioma. Pero la segunda parte de la formulación no es aristotélica... Por consiguiente, ha de iluminar a la presencia mental (la operación inmanente) en su ocultamiento (porque ella no se presenta a sí misma, sino al objeto conocido). No por eso se eliminan los actos de la inteligencia ni son substituidos por el sujeto. El sujeto comparece en el momento justo y como tiene que comparecer, es decir, sin eliminar la operación intelectual ni los hábitos; al revés, justificando los hábitos. Además, en este planteamiento el intelecto agente deja de ser una mera pieza teórica colocada en el inicio de la actividad de la inteligencia y se entiende como la unidad del esse hominis en orden al crecimiento intelectual", Curso de teoría del conocimiento, III, $2^{\mathrm{a}}$ ed., p. 12. "La inteligencia adquiere hábitos porque el intelecto agente ilumina su operar". Ibid., p. 21.

68 "Si la inteligencia es perfeccionada al recibir, iluminada por el intelecto agente, la operación que ha ejercido, crece como facultad, y su capacidad de proseguir operativamente es asegurada". Curso de teoría del conocimiento, III, $2^{\mathrm{a}}$ ed., p. 53.

69 "Conviene distinguir dos tipos de operaciones cognoscitivas: las operaciones que la inteligencia ejerce al ser informada por el objeto sensible iluminado por el intelecto agente (...), y las que ejerce perfeccionada por lo hábitos. No es el mismo iluminar objetos sensibles que manifestar la operación... Tanto los objetos de la fantasía como la operación de abstraer son iluminados por el intelecto agente. La primera iluminación permite ejercer la operación; la segunda es el hábito correspondiente a la operación de abstraer. Si se admite que el hábito es superior a la operación, el hábito abstractivo (como cualquier otro) advierte la insuficiencia de la operación correspondiente". Curso de teoría del conocimiento, IV/2, pp. 147-148. 
creciente (potencia del esse hominis, no el intelecto pasivo del naturalismo árabe), capaz de operaciones diversas, más de las que admite el aristotelismo"70.

Por otra parte, "los hábitos innatos no requieren una operación previa. Por consiguiente, los hábitos innatos dependen del intelecto agente"71. Polo no olvida que para pasar de lo sensible a lo inteligible, dado que el intelecto posible es una potencia pasiva, se requiere de un acto noético que universalice los objetos de la fantasía ${ }^{72}$. Pero, aunque en muchos lugares -de acuerdo con la tradición aristotélicaatribuya este menester al intelecto agente, en sus últimos escritos indica que esa tarea es propia de un hábito innato del que se sirve el intelecto agente a modo de instrumento ${ }^{73}$, en concreto, ese que la tradición medieval denominó sindéresis, en el que Polo descubre una dualidad, uno de cuyos miembros -al que llama ver-yoposee esta tarea respecto de los fantasmas y la inteligencia. El intelecto agente responde indirectamente (a través de la sindéresis) de la activación del intelecto posible suscitando sus actos y rindiéndolo cada vez más activo mediante los hábitos adquiridos 74 , pero no puede reducirse a ese papel. En efecto, es acto respecto de

70 Curso de teoría, III, $2^{\mathrm{a}}$ ed., p. 20. “¿cómo un principio finito puede ser operativamente infinito? Es evidente que no puede serlo él sólo; por lo tanto, el acompañamiento del intelecto agente no puede estar sólo en el inicio, en el suministro de especies impresas. Por así decirlo, el intelecto agente tiene que acompañar a la inteligencia en el mantenimiento de su operatividad". Curso de teoría del conocimiento, II, $3^{\text {a }}$ ed., p. 165. Más arriba había escrito: “¿cómo puede predicarse la infinitud de la operatividad y no de la facultad? Esta pregunta nos orienta, por un lado, hacia el intelecto agente, y, por otro, hacia la noción de hábito", Ibid., II, $3^{\mathrm{a}}$ ed., p. 160. Cfr. también: Ibid., III, $2^{\mathrm{a}}$ ed., p. 8. "El conocimiento habitual es una iluminación debida al intelecto agente -el cual es asimilable al actus essendi humano-". Nominalismo, idealismo y realismo, ed. cit., p. 187.

71 Antropología, I, ed. cit., p. 154. Y en nota al pié especifica: "según el planteamiento propuesto, el llamado intelecto agente, el lumen intellectus, es un trascendental personal. Por eso es preferible denominarlo intellectus ut co-actus o intelecto personal". Ibid., nota 4.

72 Antropología, I, ed. cit., p. 153.

73 "En Tomás de Aquino hay netas alusiones a la cuestión; por ejemplo, llama al hábito de los primeros principios "habilitas intellectus agentis". El hábito es un tener en propio, una adquisición que está estrictamente en la facultad, pero es una habilitas, una manera de iluminar del intelecto agente". Curso de teoría del conocimiento, III, $2^{\mathrm{a}}$ ed., p. 8 . Y más adelante: "Santo Tomás advierte que el intelecto agente tiene que ver con los hábitos, pero no desarrolla esta observación. El desarrollo que aquí se propone conecta con una noción tomista primordial". Ibid., $2^{\text {a }}$ ed., p. 11. "Los hábitos son el perfeccionamiento, el reforzamiento de la facultad en cuanto tal. Referidos al intelecto agente, los hábitos son su habilitas. Las operaciones intelectuales siguen en tanto que la potencia intelectual está perfeccionada por los hábitos. En este sentido puede decirse que siguen también al intelecto agente de acuerdo con su habilitas". Ibid., II, $3^{\text {a }}$ ed., p. 165. "No parece que el valor iluminante del intelecto agente se reduzca a iluminar los objetos sensibles (ni a las operaciones), no es preciso admitir que dicha iluminación corra directamente a su cargo: es perfectamente posible que dicha iluminación tenga lugar de modo habitual. Esto abre el amplio campo temático de los hábitos innatos". Antropología, I, p. 153.

${ }^{74} \mathrm{Cfr}$. La libertad, I, p. 89. Y en otra parte añade: "El intelecto agente es más de lo que dice Aristóteles (no es lo que dice Aristóteles), quien no ha visto su valor iluminante de actos y, por tanto, no lo ha puesto en relación con el conocimiento habitual. Y como estimo que hay que hacerlo, lo formulo axiomáticamente: el conocimiento habitual es debido al intelecto agente. El axioma de los hábitos dice que la inteligencia es susceptible de hábitos; ahora se añade: los hábitos son posibles por el intelecto agen- 
todo otro conocer intelectual humano inferior ${ }^{75}$, pero, precisamente porque se puede dar el acto sin la activación de lo potencial, se puede explicar el intelecto agente al margen de la activación de la inteligencia. El intelecto en acto está al margen de toda operación y existe aunque aquella no exista. Él es el auténtico a priori del conocimiento humano porque el entendimiento agente constituye la inteligibilidad en acto: "la inteligencia humana es imposible sin intelecto agente. El intelecto agente es un acto y por ello es superior a la inteligencia" 76 .

Con todo, si bien el intelecto agente es raíz de la iluminación de toda instancia cognoscitiva inferior, no es ese su fin o tema, pues el tema del conocer humano superior no puede ser nada inferior a él: el tema del conocer personal no puede ser impersonal. Ahora bien, como tal conocer no puede carecer de tema (sería absurdo $^{77}$ ), Polo indaga cual es su tema propio ${ }^{78}$ y cómo se corresponde cognoscitivamente con él. Ese tema tampoco puede ser él mismo intellectus agens, porque ningún conocer humano es reflexivo respecto de sí, ya que método cognoscitivo y tema conocido constituyen en las criaturas una dualidad que no puede ser reducida a identidad79. En definitiva, para Polo, "el intellectus ut co-actus se corresponde con un tema superior y distinto" 80 . Con lo que precede se niega de plano que el intelecto agente no sea cognoscitivo, tesis bastante asumida por parte de no pocos comentadores renacentistas ${ }^{81}$. A la par, al admitir la distinción real tomista entre acto de

te. Así se completa la formulación del axioma. Pero la segunda parte de la formulación no es aristotélica... Por consiguiente, ha de iluminar a la presencia mental (la operación inmanente) en su ocultamiento (porque ella no se presenta a sí misma, sino al objeto conocido). No por eso se eliminan los actos de la inteligencia ni son substituidos por el sujeto. El sujeto comparece en el momento justo y como tiene que comparecer, es decir, sin eliminar la operación intelectual ni los hábitos; al revés, justificando los hábitos. Además, en este planteamiento el intelecto agente deja de ser una mera pieza teórica colocada en el inicio de la actividad de la inteligencia y se entiende como la unidad del esse hominis en orden al crecimiento intelectual". Curso de teoría del conocimiento, III, $2^{\mathrm{a}}$ ed., p. 12.

75 "El intelecto agente preside la intelección" Antropología, I, 52. "la inteligencia humana sin intelecto agente no podría pasar al acto, no podría ser principio operativo. Dicho de otro modo, la inteligencia no es una facultad sola: requiere un «acompañante», un acto que concurre con su carácter estrictamente potencial". Curso de teoría del conocimiento, II, ed. cit., p. 155.

${ }^{76}$ Curso de teoría del conocimiento, II, $3^{\text {a }}$ ed., p. 170.

77 Antropología, I, ed. cit., pp. 224-225.

78 "En los pasajes de la Secunda Secundae de la Summa Theologiae en los que Tomás de Aquino trata del conocimiento profético, la apelación al intelecto agente es frecuente. Sin caer en una exégesis abusiva de su planteamiento, ello permite sostener que Tomás de Aquino entiende también que el intelecto agente se corresponde con un tema propio. Pero para eso, insisto, no basta con el intelecto personal humano aislado, pues la intelección profética es sobrenatural. En suma, el intelecto humano es trascendental, personal, carente de réplica, pero orientado hacia ella". Antropología, I, ed. cit., pp. 226.

79 "El intellectus ut co-actus es el núcleo del saber, desde el cual -radicalmente- se ejercen las operaciones y los hábitos; pero él no es estrictamente ninguno de ellos, por ser el acto intelectual superior. Que la persona sea el acto intelectual superior no comporta la identidad intelectual, pues la identidad es exclusiva de Dios". Antropología, I, ed. cit., p. 224.

80 Antropología, I, ed. cit., p. 160.

81 "En la filosofía tradicional... el intelecto agente es interpretado, a su vez, como fundamento subjetivo inconsciente del conocimiento humano". El ser, I, $1^{\mathrm{a}}$ ed., p. 24, nota 7; $2^{\mathrm{a}}$ ed. p. 26, nota 7. 
ser y esencia en el conocer humano, se puede distinguir entre la luz noética propia del acto de ser personal respecto de esos modos de conocer que pertenecen a la esencia humana ${ }^{82}$. Polo describe la luz del intelecto agente como transparente, a distinción del resto del conocer humano, que son luces iluminantes: "se distinguen las luces iluminantes y la transparencia del intelecto personal, que es la más separada, puesto que busca el tema que la transciende" 83 .

El Profesor Polo describe la transparencia del intelecto agente como "luz intrínsecamente atravesada de luz" 84 , o también como "interna diafanidad" 85 , como "insistir en la apertura hacia dentro"86, "limpidez"87, "luz en la luz"88. Asimismo indica que, "transparencia equivale a co-acto, es decir, a intimidad" 89 . Todos esos modos de decir se toman como equivalentes del intelecto agente o intellectus ut coactus $^{90}$. "Si el intelecto es de suyo pura luz eso es lo que significa transparencia, su conocimiento debe correr a cargo de un método translúcido, esto es, de la estricta limpidez intelectual. Por eso se asevera que el hábito de sabiduría es la transparencia metódica y el intelecto la transparencia temática, de tal modo que 'alcanzar el co-acto personal equivale a su propia transparencia. El intellectus ut co-actus es la luz penetrada de luz"'91. Para el autor, el hábito de sabiduría es el método noéti-

82 "Si esa distinción se descubre, se ha de admitir también la distinción del intelecto personal con la intelección esencial, esto es, la distinción de la luz transparente que busca y las luces iluminantes que encuentran". Antropología, I, ed. cit., 224-225. "Se podría afirmar, apurando un poco, que, en el plano de consideración aristotélico, el entendimiento agente constituye la inteligibilidad en acto, no la misma presencia, que sería más bien del orden del entendimiento paciente". El acceso al ser, ed. cit., p. 312. 83 Antropología, II, ed. cit., 25. Bajo el texto citado anota: "con la equiparación del intelecto agente al intelecto personal se resuelve la grave cuestión que aparece en Aristóteles al negar que el intelecto agente sea cognoscente", nota 28. "El intelecto personal no es una luz iluminante, sino una luz transparente". Antropología I, ed. cit., p. 214. "El intelecto personal no alcanza su tema". Ibid., p. 216

También la fe está separada de su tema, el cual se llama misterio. La fe se expresa en símbolos; pero el tema de la fe no es el símbolo, sino aquello a lo que el símbolo se refiere. Por este doble motivo se dice que la fe es una luz oscura.

${ }^{84}$ Antropología, I, ed. cit., p. 216.

85 Ibid.

86 Antropología, I, ed. cit., p. 181.

87 Ibid., I, p. 216.

88 Ibid., I, p. 223.

89 Ibid., I, p. 197.

90 "La transparencia intelectual, que denomino intellectus ut co-actus". Antropología, I, p. 203.

$91 \mathrm{Ibid}$., p. 324. La referencia a Polo pertenece a su Antropología, I, 180. Polo explica esta cuestión de la siguiente forma: "el método es interno al tema, en tanto que el tema se alcanza. En atención a ello, se describe el tema como pura transparencia. La transparencia tira del método [...]. Transparencia equivale a co-acto, es decir, a intimidad. Por eso, tanto da decir que el tema es interior al método como que el método es interior al tema; la transparencia no es temática si no es metódica, y no es metódica si no es temática [...]. El carácter de además es puro sobrar. No lo sería sin dualidad, sin inclusión. Pero dicha inclusión es la intensidad de la transparencia. La dualidad del carácter de además no es oclusiva, no comporta determinación. Todo lo contrario: de acuerdo con su dualidad, el carácter de 
co cuyo tema es el intelecto agente, y éste es, a su vez, el método cuyo tema es el ser divino 92 . En suma, como manifiesta el título de la reciente breve publicación poliana, "La persona como ser cognoscente" 93 , la persona humana no sólo 'tiene' conocer, sino que lo 'es', y tal conocer es el intelecto agente.

D. Las notas aristotélicas del intelecto agente. Por lo que respecta a los rasgos que el Estagirita atribuyó al intelecto agente, a saber, 'separable, sin mezcla e impasible, siendo como es acto por su propia entidad', Polo se fija, sobre todo, en la primera: "Según Aristóteles, el intelecto está enteramente separado. Estar separado de todo significa distinguirse de lo inteligido. En tanto que el intellectus ut actus puede ser en cierto modo todas las cosas, las 'hace' inteligibles; por eso Aristóteles habla de noûs poietikós... El intellectus ut co-actus se distingue a priori de lo conocido. Si no fuera distinto, no se conocería nada, porque al intelecto le faltaría lo más característico, es decir, la transparencia: la luz intrínsecamente atravesada de luz. Es preciso distinguir lo inteligido en acto y el intelecto como acto, pues lo primero es imposible sin lo segundo. Ahora bien, si el intellectus ut co-actus no se distingue de lo inteligido en acto, se oscurecería, perdería su interna diafanidad, desde la cual puede serlo todo al dar lugar a la iluminación de ello. Según la libertad, el intelecto se distingue radicalmente de lo inteligido. Sólo así es posible la verdad trascendental. El intelecto es trascendental y, correlativamente, también lo es la verdad; si el intelecto no fuera trascendental, la verdad tampoco lo sería"94.

Para Polo es claro que el intelecto agente es 'sin mezcla', es decir, carente de órgano corporal, y que es, asimismo, 'impasible', a distinción de la inteligencia o intelecto 'paciente'. En cuanto a la expresión aristotélica 'es acto por su propia entidad', ésta denota, para Polo, que el intelecto agente equivale al co-acto de ser personal humano. Este pensador aristotélico también conoce, obviamente, que es 'más excelso el agente que el paciente', pero no comenta en directo los siguientes pasajes del filósofo de Atenas: a) Uno, el que declara: 'desde el punto de vista de cada individuo la ciencia en potencia es anterior en cuanto al tiempo, pero desde el punto de vista del universo en general no es anterior ni siquiera en cuanto al tiempo'. b) Otro, en el que se enseña: 'no ocurre, desde luego, que el intelecto entienda a veces y a veces deje de entender', lo cual abre la pregunta de que -dado que se

además está, permanece, abierto. De donde se sigue que dicha dualidad es metódica y temática: es un método que es un tema y un tema que es un método; no una oclusión o autodeterminación, sino la intensidad de la transparencia". Antropología, I, ed. cit., p. 197.

92 "Dios es el tema del acto cognoscitivo superior humano en tanto que en ese tema está incluido también, temáticamente, dicho acto cognoscitivo: la persona conoce a Dios en tanto que conoce como Dios la conoce. En este sentido, puede hablarse de la comunicación donal de un tema doble: Dios e intelecto personal humano. Así pues, la llamada contemplación beatífica de Dios implica el propio conocimiento, sin que sea necesaria una reflexión que arranque de éste". Antropología, I, ed. cit., p. 230 .

93 Cfr. Polo, L.: "La persona como ser cognoscente”, Studia Poliana, 8, 2006, pp. 53-72.

94 Antropología, I, ed. cit., p. 119. 
hace equivaler el intelecto agente al acto de ser humano, que éste existe desde el inicio, y que no puede carecer de tema- ¿cómo es la apertura cognoscitiva del intelecto a Dios desde el inicio de su existencia?, pues, desde luego, aunque inicialmente sea búsqueda, somos inconscientes de ello. c) Tampoco se pronuncia in recto acerca del significado de esta dicción aristotélica: 'una vez separado es sólo aquello que en realidad es y únicamente esto es inmortal y eterno', ni de la siguiente y última del texto aristotélico: d) 'Nosotros, sin embargo, no somos capaces de recordarlo, porque tal principio es impasible, mientras que el intelecto pasivo es corruptible y sin él nada entiende'.

\section{El intelecto agente según los discípulos de ambos filósofos}

A continuación repasaremos brevemente el parecer de algunos discípulos de los dos pensadores precedentes sobre este tema. De Canals, sólo atendemos a uno: Juan García Muro. De Polo, en cambio, a cinco: Ignacio Falgueras, Ricardo Yepes, Juan A. García González, Salvador Piá Tarazona y José Ignacio Murillo.

a) Juan García del Muro. En su libro Ser y conocer 95 , fruto de su tesis doctoral, dedica la Sección segunda al entendimiento agente. Parte adjudicándole el tradicional papel de abstraer: "la actividad iluminadora del intelecto agente transforma la imagen sensible en especie inteligible" 96 , es decir, la eleva, ennoblece o espiritualiza: "la abstracción las hace existir (a las especies) de un modo más alto, es decir, superior" 97 . Abstraer no es sólo separar de las condiciones sensibles, sino hacer las cosas 'in esse intelligibile'. No es una manifestación de indigencia, sino 'una comunicación del ser inmaterial'. Con Tomás de Aquino, Juan describe al intelecto agente como cierta 'virtus', y añade que su "luz procede de la mente humana en cuanto que es actualmente inteligible, intrínsecamente infinita por participar del ser en modo perfecto, en modo intelectual"98. Por tanto, no la identifica con el acto de ser humano, sino que dice participar de él. Sin embargo, a continuación añade algo sorprendente: "La luz o acto del entendimiento agente pertenece al hombre pero le sobrepasa, transciende sus propios límites entitativos" $"$. ¿Quiere esto decir que no es humana, sino extrínseca? No, porque -como ha indicado- 'participa del ser humano’. Pero entonces, ¿por qué le sobrepasa? En la respuesta encontramos la

\footnotetext{
95 Cfr. García del Muro, J.: Ser y conocer, Barcelona, PPU., 1992.

96 Ibid., p. 149. Y sigue: "Abstraer, para el entendimiento agente, no es sólo separar, prescindir de lo material y sus condiciones, como si el objeto se empobreciera, sino al contrario, la acción del entendimiento agente es enriquecedora, la inmaterialidad de la especie inteligible es efecto del mismo entendimiento que le comunica su propio modo de ser". Ibid., p. 150.
}

97 Ibid., p. 152.

98 Ibid., p. 158

99 Ibid., p. 160. 
palabra 'enigma', denotando que el alma es 'infinita'. ¿Qué sentido tiene esta infinitud? Que "el hombre, a pesar de ser pura potencia en el orden intelectual, posee el ser de tal modo que es acto de los inteligibles, su grado de participación en el ser le otorga la actual ilimitación intrínseca y la consiguiente capacidad intelectual. Es patente la dependencia de la teoría de la luz del entendimiento agente connatural a la propia alma, de la noción de 'esse' como acto de todo acto"100. Como se puede apreciar, Juan -como su maestro Canals- vincula el intelecto agente al esse hominis y, en este sentido concibe al alma no sólo como potencial, sino también activa.

A lo que precede García del Muro aplica el consabido 'nihil est respectu eiusdem in actu et in potentia', lo que en el plano del conocimiento denota que en el alma existe una dimensión potencial respecto de los inteligibles, y otra distinta que es activa. Si la potencial pertenece a la esencia del alma, "el ser del alma es el acto de los mismos inteligibles"101. Sabe que la asimilación aristotélica del intelecto agente al 'hábito' es para evitar su designación como 'potencia', lo cual manifiesta "su carácter esencialmente actual"102, y sabe también que, pese a eso, Tomás de Aquino lo describía como 'potencia' (otras veces como 'virtus'); pero Juan afirma que "el acto del entendimiento agente emana de la posesión inmaterial del ser"103, lo cual significa que "el alma humana es intelectual en acto por ser inmaterial en acto"104, es decir, que hay que "atribuir al alma una luz, acto"105. El alma, por tanto, está compuesta, de acto (luz cognoscitiva) y potencia cognoscitiva: "el alma humana, a la vez que potencia, es acto" 106 . La del intelecto agente es "natural' o 'connatural', un 'entender en acto', previo al conocer de la potencia107. A continuación deduce una conclusión de dos premisas tomistas: una, 'el ser el acto de toda forma'; otra, 'el entender no es otra cosa que ser': "su propio acto (del hombre), el entender, es simplemente ser"108. Con otras palabras: el ser del hombre "es un conocimiento intelectual permanente"109. La conclusión es acertada. Pero seguidamente identifica esta luz con el conocimiento nativo que el alma tiene de sí misma, identificación apresurada, porque el acto de ser conocido (tema) desborda nuestro conocerlo (método). En efecto, la criatura es dual, no idéntica, y la dualidad debe ser respetada también en teoría del conocimiento, pues ningún método cognoscitivo es idéntico al tema por él conocido.

\footnotetext{
100 Ibid., p. 162.

101 Ibid., p. 164.

102 Ibid., p. 165.

103 Ibid., p. 168.

104 Ibid., p. 168.

105 Ibid., p. 171.

106 Ibid.

107 Cfr. Ibid., pp. 172-3.

108 Ibid., p. 174. El matiz que añade es sumamente clarificador: "el entender a que nos referimos no puede consistir en la intelección objetiva, pues ésta es consecuencia de aquél, lo presupone". Ibid. 109 Ibid., p. 175.
} 
b) Ignacio Falgueras. Este autor, uno de los primeros discípulos polianos, en su escrito Esbozo de una filosofía trascendental: introducción 110 , primero aclara el significado que él atribuye a 'trascendental', que no equivale a lo que por este término se ha entendido en la filosofía moderna (Kant, Schelling, Hegel) y contemporánea (Husserl, Heidegger, Jaspers, Sartre), sino que denota a "la filosofia que investiga los trascendentales" 111 , es decir, las realidades que trascienden el orden 'predicamental' y que, siendo plurales, "son activas y relativas o relacionales unas con otras"112. Lo que precede implica que los trascendentales son realidades, no ideas, y no cualesquiera realidades, sino las últimas ${ }^{113}$. Los métodos noéticos que propone para alcanzar dichas realidades son asimismo plurales (y trascienden de diversos modos el conocer objetivo, el que forma ideas). Uno de ellos es el antropológico, inaugurado -afirma- por Agustín de Hipona, y olvidado desde Escoto (quien dota a los trascendentales de sentido lógico) hasta Polo (que abandona la objetividad para acceder a las realidades trascendentales metafísicas y personales). Pero el antropológico no es el único, pues si el hombre transciende el límite cognoscitivo del objeto pensado -sigue Falgueras-, encuentra dos ámbitos de realidades trascendentes: las metafísicas y las antropológicas ${ }^{114}$. A los trascendentales primeros los llama "condicionales" porque dependen de los segundos, y a éstos "incondicionales". Los primeros dependen, porque no cabe ser sin co-ser personal; verdad sin conocer personal; bien sin amor personal. Por vía antropológica, una de las realidades que transcienden al conocer objetivo es lo que el autor llama "el entender" 115 , que coincide con el intelecto agente. Es claro que este entender es distinto del conocer de la razón, pues en caso contrario no lo trascendería.

Por su parte, en su trabajo Esbozo de una filosofia trascendental (I) ${ }^{116}$-que incluye y amplía su escrito precedente- dedica un apartado a la 'Descripción de la realidad del entender trascendental'. Distingue asimismo entre entender y comprender. Para Falgueras comprender es 'objetivar', es decir, el conocer que forma o presenta un objeto pensado al conocer. Lo considera menos que entender, al que des-

110 Falgueras, I.: "Esbozo de una filosofía trascendental: introducción", I., Anuario Filosófico, XXIX/3, 1996, pp. 481-508.

111 Ibid., p. 484.

112 Ibid., p. 486.

113 "En pocas palabras, filosofía trascendental significa, para mí, búsqueda pura de las realidades últimas, plurales y relacionales". Ibid.

114 "Hay, pues, dos sentidos del trascender: el trascender humano, activo (descubierto por Agustín), y el trascender irreferente y absoluto de los principios de la naturaleza (descubierto por los griegos)... Lo trascendente ofrece, por lo tanto, dos caras distintas a la investigación humana: la faz metafísica y la antropológica". Ibid., p.495.

115 Cfr. Ibid., 511.

116 Cfr. Falgueras, I.: Esbozo de una filosofia trascendental (I), Cuadernos de Anuario Filosófico, Serie Universitaria, no 36, Pamplona, Servicio de Publicaciones de la Universidad de Navarra 1996. 
cribe como "un surgir originario y activo de la alteridad en el ser"117, es decir, un conocer relativo al ser en el 'plano mismo del acto'. "Entender es acoger el ser haciéndolo lucir"118; se trata de "la comunicación mutua del ser y de su noticia"119; "entender es la riqueza del ser"120. Como se puede apreciar-y al margen de los términos que usa-, el autor alude a un conocer humano que no está en el orden de la essentia, sino en el del actus essendi, que podemos hacer equivaler al intellectus agens, aunque en estos textos no se hable explícitamente de él.

c) Ricardo Yepes. Este discípulo poliano, uno de los primeros que ordenó los trabajos del maestro, posee algunos escritos en los que interpreta y comenta la filosofía de Polo. Así, en su escrito "La antropología trascendental de Leonardo Polo"121 alude al intelecto agente: "los trascendentales personales no estarían completos sin el intelecto"122, que sabe equivalente al "núcleo del saber'. Por su parte, en su colaboración al Congreso Internacional en homenaje al profesor Polo de 1996, que se titula "Persona: intimidad, don y libertad nativa. Hacia una antropología de los trascendentales personales" 123 , curiosamente el tema del intelecto personal no aparece ni en el título, señal de que, o no lo tuvo en cuenta, o no lo entendió, pese a estar perfilado en los escritos polianos de antropología trascendental a los que tuvo acceso. Y otro tanto encontramos en sus escritos de índole personal. Por ejemplo, en su difundido libro Fundamentos de antropología. Un ideal de la existencia humana ${ }^{124}$, en el cap. 2, 'La vida intelectiva', se expone la inteligencia (entendimiento posible), pero no alude al conocer personal (entendimiento agente). Tampoco en el cap. 3 'La persona', en el que, entre las notas 'que definen a la persona' pone 'la intimidad, la manifestación: el cuerpo, el diálogo: la intersubjetividad, el dar, la libertad'. Sin embargo, de éstas, sólo la primera y las dos últimas son distintivas del acto de ser personal (pues las otras describen, o bien a la naturaleza orgánica del hombre, o bien a la esencia humana). Como se ve, no hay alusión alguna al intelecto personal. Lo que precede indica, por una parte, que el autor confunde o mezcla lo propio del actus essendi con lo característico de la essentia hominis $\mathrm{y}$, por otra, que no repara en la trascendentalidad del núcleo del saber. A su vez, si

\footnotetext{
117 Op. cit., p. 49.

118 Ibid., p. 53.

119 Ibid.

120 Ibid., p. 61.

121 Cfr. Yepes, R.: "La antropología trascendental de Leonardo Polo", AAVV., El pensamiento de Leonardo Polo, Cuadernos de Anuario Filosófico, Serie Universitaria, $\mathrm{n}^{\circ}$ 11, Pamplona, Servicio de Publicaciones de la Universidad de Navarra, 1991, pp. 61-84.

122 Ibid., p. 70.

123 Cfr. Yepes, R.: "Persona: intimidad, don y libertad nativa. Hacia una antropología de los trascendentales personales". Anuario Filosófico, XXIX/3, 1996, pp. 1077-1108.

124 Cfr. Yepes, R.: Fundamentos de antropología. Un ideal de la existencia humana, Pamplona, Eunsa, 1996.
} 
se repasa su escrito póstumo La persona y su intimidad ${ }^{125}$, se observa otro tanto, a saber, que el tema del conocer personal (intelecto agente) no está ni aludido. En suma, estamos ante un autor que domina, como pocos, las diversas dimensiones de la esencia humana, pero al que le supera lo trascendental o propio del acto de ser del hombre.

d) Juan Agustín García González. En su escrito "Discusión de la noción de entendimiento coagente" 126 revela que el propósito de su trabajo es aclarar que el intelecto agente -al que Polo también llama 'intelectus ut co-actus, y García 'intelecto co-agente' - es un trascendental personal. Para J. A. García (a diferencia de Falgueras) Agustín de Hipona posee una visión de lo trascendental humano de cariz platónico. Por eso indica que el intelecto personal (no se trata del conocer de la inteligencia, razón o entendimiento) se alcanza trascendiendo, no la 'verdad' conocida por la razón -el objeto conocido-, sino el propio 'acto' de conocer racional. Por otra parte, Juan A. García sostiene que el tema de este intelecto es lo inagotable, lo inabarcable, lo reservado, lo cual equivale a señalar "que no puede haber un acto cognoscitivo que no sea tal, es decir, que no alcance algún conocimiento; pues en otro caso, más que de un acto cognoscitivo hablaríamos de un primer principio del conocimiento" 127 , pero un primer principio del conocimiento que no conozca es absurdo, pues equivale a deducir el conocer de la ignorancia128. Juan A. García sabe que la inabarcabilidad es un modo de llamar al ser divino. Por eso el ser personal humano "comporta su heteroreferencia"129, lo cual niega de plano -y en el más alto nivella reciente y manida teoría de la reflexio (o reditio, cuya cadencia neoplatónica es neta), pues si el conocer personal se pudiese conocer completamente a sí mismo tras una supuesta vuelta reflexiva completa, por una parte se sacaría el saber de la ignorancia, y por otra, Dios estaría de más. Pero ambas hipótesis son absurdas, puesto que, por un lado, es palmario, por experiencial, que no nos conocemos enteramente; y por otro, que la persona es copersona, coexistencia con Dios. ¿Qué significado tiene esto? García lo desvela: "la antropología sólo puede ser trascendental cuando no pivota ya sobre el hombre, sino que se abre a Dios como a su dualidad correspondiente"130, apertura o búsqueda que corre a cargo del conocer personal.

125 Cfr. Yepes, R.: La persona y su intimidad, Cuadernos de Anuario Filosófico, Serie Universitaria n ${ }^{\circ}$ 48, Pamplona, Servicio de Publicaciones de la Universidad de Navarra, 1997.

126 Cfr. García González, J. A.: "Discusión de la noción de entendimiento coagente", Studia Poliana, 2, 2000, pp. 51-71

127 Ibid., p. 57.

128 En efecto, un pensador formado en la tradición clásica medieval que entendiese por ese primer principio el actus essendi hominis, debería educir el conocer de tal acto de ser, pero ante esa deducción se le plantea la siguiente pregunta: ¿Cómo es el acto de ser del hombre para que de él nazca el conocer? A la cual sólo puede responder positivamente de dos modos (aunque también puede no responder o revelar que no sabe): a) El acto de ser humano es cognoscente, con lo que se soluciona el problema. b) No es cognoscitivo, con lo que la dificultad se le torna insoluble.

129 Ibid.

130 Ibid. 
El conocer personal humano se abre como método cognoscitivo al Dios personal como tema conocido, pero éste, a su vez, se abre como método al ser humano como tema. Por eso "el planteamiento poliano se apoya en que el hombre sólo puede conocer a Dios si Dios lo conoce: el conocimiento por parte de Dios de la persona humana es imprescindible para que la persona humana conozca a Dios"131. Como el conocer personal humano es libre (es coacto con la libertad personal) puede dejar de conocer su tema, es decir, abandonar la búsqueda. Pero en esa tesitura la respuesta divina pasa a ser un "no os conozco"132. Como se ve, en esta correspondencia con el conocer personal humano, Dios no aparece como inteligible (more platónico), sino como 'inteligente' (al estilo aristotélico). En suma, "el intelecto coagente no se dualiza con un tema, sino con otro intelecto, con el intelecto divino"133. El hombre requiere del conocer divino para conocerse, porque como afirma Polo "en el hombre el conocer como ser equivale a la persona, y la persona humana como co-actus o co-existencia no es realmente idéntica"134, ya que la identidad o simplicidad es exclusivamente divina, pues en lo creado se da siempre la distinción real entre acto de ser y esencia. El conocer humano, también a nivel personal, es dual: conocer-conocido, porque el hombre jamás deja de ser criatura. Si el conocer personal humano mira a Dios, y requiere ser conocido por él, no es sólo 'agente' (como la tradición aristotélica admite), sino 'coagente'. De este modo se entiende mejor por qué Tomás de Aquino indicaba que la luz del intelecto agente (...) procede en el alma, sin duda, como del primer origen,... de Dios"135, pero se trata de un proceder que no se desliga del origen, a menos que libremente quiera, y que, si se desliga, deviene absurdo en su ser. De otro modo: el hombre (cada uno) sin Dios es incomprensible; está hecho para Dios, para ser-con o coexistir con él.

e) José Ignacio Murillo. En su libro Operación, hábito y reflexión. El conocimiento en la antropología de Tomás de Aquino 136 (resultado de su tesis doctoral), alude varias veces al intelecto agente. En una de ellas se indica que este intelecto es

131 Ibid., p. 58.

132 Mt., XXV, 14. Por el contrario, no cesar en la búsqueda obtiene la respuesta divina del "conoceréis como sois conocidos". I Cor., XIII, 12.

133 Ibid., p. 62.

134 Polo, L.: Antropología, I, ed. cit., p. 128.

135 Tomás de Aquino, De Ver., q. 10, a. 6, co. En otros lugares añade que el intelecto agente es "cierta virtud participada de alguna sustancia superior, a saber, de Dios". Q. D. De Anima, q. un., a. 5, co; "decimos que la luz del intelecto agente, de la que habla Aristóteles, es impresa en nosotros inmediatamente por Dios". De Spiritualibus creaturis, q. 10, co; "es llamado por Aristóteles luz recibida en nuestra alma por Dios". Ibid., q. 10, co; "es necesario que por encima del alma humana exista algún intelecto del que dependa su entender (el del intelecto agente)". Ibid., q. 10, co. "es propio de Dios iluminar a los hombres imprimiéndoles la luz natural del intelecto agente, y sobre ésta, la luz de la gracia y de la gloria". Ibid., q. 10, ad 1.

136 Cfr. Murillo, J.I.: Operación, hábito y reflexión. El conocimiento en la antropología de Tomás de Aquino, Pamplona, Eunsa, 1998. 
el correlato adecuado para activar la potencia intelectual (intelecto posible). Tras aludir al texto aristotélico (De anima, 1. III, cap. 5), atiende a la interpretación tomista, según la cual se considera 'potencia activa' a tal intelecto, amén de asemejarlo (como el Estagirita) al hábito ${ }^{137}$, pero Murillo no critica la inoportuna noción de 'potencia activa', pese a que sabe que Aristóteles no emplea sino la de 'acto'. En otro lugar de la misma obra alude al intelecto agente como a un "una dimensión activa... un acto previo a toda operación intelectual" 138 , de la que no sólo depende la iluminación de las formas de la fantasía (abstracción), sino la misma operación inmanente del intelecto posible, es decir, la activación de la razón o inteligencia. Más adelante vuelve a poner en correlación de dependencia la operación inmanente con el intelecto agente, pero añade que el intelecto posible está vuelto al agente, y que tal retracción es lo que Tomás de Aquino denomina 'intellectus in habitu' 139 . Añade que es en ese sentido como hay que entender la llamada 'reditio' o 'reflexio', a saber, no que el intelecto posible se vuelva sobre sí mismo, o que sus actos sean un giro autoreferente, sino que el intelecto posible depende del agente, el cual le permite conocer más, es decir, formar hábitos adquiridos. Por último, al tratar del conocimiento de la propia existencia, hace equivaler el intelecto agente al sujeto cognoscente y lo designa como 'principio intelectual' 140 . Como se ve, no hay una explicitita formulación de que el intelecto agente esté a nivel de actus essendi hominis, entre otras cosas, porque este trabajo está centrado en el corpus tomista, y el de Aquino no es explícito al respecto. Con todo, se deja entender.

Por otro lado, en su posterior trabajo "Conocimiento personal y conocimiento racional en la antropología trascendental de Leonardo Polo"141, centrado en la distinción entre los dos tipos de conocimientos mencionados según el pensamiento de Polo, insinúa que el intelecto agente está a nivel de esse hominis. Para exponerlo, parte de la sentencia poliana 'el yo pensado no piensa'. Con ella manifiesta que el yo pensado no es el real -no es el yo pensante-, sino el ideal, es decir, una idea pensada. Por tanto, si cabe hablar de dos 'yoes', el pensante y el pensado, es porque existen, al menos, dos niveles noéticos irreductibles. Si uno de ellos es ideal, el otro es real. Ahora bien, ¿en qué radica su realidad? Murillo -cuyo pensamiento no es directo- revisa primero sintéticamente los intentos cognoscitivos de sí, tanto en el pensamiento clásico griego y medieval como en el moderno y contemporáneo. Tras ello, y al final, aborda 'la distinción poliana entre el conocimiento personal y el racional'. Termina afirmado que "la persona es acto de entender" 142 , distinto, por

\footnotetext{
137 Cfr. Ibid., pp. 41 ss.

138 Cfr. Ibid., p. 138.

139 Cfr. Ibid., p. 148.

140 Cfr. Ibid., p. 185.

141 Cfr. Murillo, J.I.: "Conocimiento personal y conocimiento racional en la antropología trascendental de Leonardo Polo", Studia Poliana, 13, 2011, pp. 69-84.

142 Cfr. Ibid., p. 82.
} 
superior, al conocer de su esencia (a la que pertenece el conocer de la razón). Por tanto, la persona es acto de ser cognoscente.

f) Salvador Piá Tarazona. Este joven discípulo de Polo, en "Sobre las dualidades intelectuales superiores" 143 estudia (entre otros niveles cognoscitivos humanos) el hábito de sabiduría que se 'dualiza' (vincula) con el intelecto agente o conocer personal. Dicho hábito no es ningún mirar hacia fuera, sino que insiste hacia adentro. ¿Qué conoce? "El hábito de sabiduría es el método (cognoscitivo) que tiene como tema el intelecto personal"144. Piá nota que el intelecto agente no es un conocer como los demás, es decir, una luz 'iluminante', sino una luz transparente. En consecuencia, la tradicional costumbre de adjudicarle al intelecto agente el papel de abstraer -que significa 'iluminar' las especies de la sensibilidad intermedia a la par que 'iluminar' (o activar) al intelecto posible-, debe ser revisada. En efecto, ese papel se puede relegar a un hábito innato del intelecto agente, pero no debe atribuírsele a él. Con Polo afirma que tal hábito innato es la sindéresis, instrumento nativo con el que la persona o intimidad humana se abre a todo aquello que es suyo y está a su disposición (su esencia inmaterial y su naturaleza orgánica). De este modo se entiende por qué el tema del conocer humano superior no puede ser ningún asunto inferior a él (tampoco él mismo, porque la identidad o reflexión debe ser excluida en teoría del conocimiento, ya que todo método cognoscitivo siempre es distinto del tema conocido145). El hábito de sabiduría es distinto del intelecto agente; son dos actos distintos que tienen temas distintos. El hábito alcanza a conocer el conocer personal (intelecto agente) y a los demás radicales personales (la coexistencia libre y el amor personal), mientras que el tema del intelecto agente es el ser divino146.

Por otro lado, la última parte de su formidable trabajo El hombre como ser dual. Estudio de las dualidades radicales según la Antropología trascendental de Leonardo Polo 147 (producto de su tesis) está dedicada al estudio del intelecto agente, al que llama 'intelecto personal'. También aquí Piá distingue a nivel intelectual

143 Cfr. Piá Tarazona, S.: "Sobre las dualidades intelectuales superiores", Studia Poliana, 3, 2001, pp. $145-68$.

144 Ibid., p. 158. Y más adelante añade: “el hábito de sabiduría y el intelecto personal son respectivamente el valor metódico y el valor temático del carácter de además". Ibid., p. 169. 'Además' significa, para Polo, crecimiento irrestricto. Toma ese adverbio para describir a la persona humana, que es crecimiento respecto de Dios. Más abajo añade Piá: "el hábito de sabiduría es solidario con el intelecto personal, pero no son el mismo acto cognoscitivo". Ibid., p. 161.

145 "El mejor modo de estudiar el conocimiento humano se lleva a cabo desde la dualidad metódicotemática". Ibid., 164; "la pura transparencia excluye de sí la reflexión más que cualquier otro acto cognoscitivo". Ibid.

146 "Debe decirse que dicho tema es inabarcable por transcendente. Si bien se mira, esto significa que la inabarcabilidad de tal apertura transcendente indica que la persona humana es creada en tanto que remite a Dios: la estricta Transcendencia". Ibid., p. 164.

147 Cfr. Piá Tarazona, S.: El hombre como ser dual. Estudio de las dualidades radicales según la Antropología trascendental de Leonardo Polo, Pamplona, Eunsa, 2002, pp. 294-324 y pp. 400-413 
entre método y tema: "en la intelección trascendental del intelecto personal se debe distinguir entre el método y el tema, pues éstos nunca se identifican realmente en el hombre"148. El método es el hábito de sabiduría; el tema, el intelecto personal. El intelecto es persona; el hábito es de la persona. El tema es superior al método. Por medio de dicho hábito sabemos que somos una 'verdad' o 'sentido personal' distinto, es decir, un conocer personal singular y novedoso. Conocer la transparencia que es el conocer personal corre a cargo de un método que no es 'iluminante', sino 'traslúcido' o 'solidario' con dicho conocer. El método sabe que somos un sentido distinto, pero no sabe enteramente qué sentido somos, porque el tema desborda el método. Consecuentemente, para conocer el sentido completo que somos como personas, el conocer personal debe abrirse a un conocer superior a él que sea capaz de manifestarle por entero dicho sentido, es decir, el propio conocer personal debe tomarse como método cognoscitivo respecto de una persona distinta que conozca plenamente a aquél como tema.

A esto Piá lo denomina "reconocimiento interpersonal"149, relación que implica dualidad noética de índole trascendental, es decir, la existencia de dos personas cognoscentes. Si la persona humana no llega enteramente a saber por sí sola quién es, porque carece en su interior de otra persona que se lo manifieste -"carece de réplica personal intelectual en su interior" 150 , entonces, o "la carencia de réplica personal no es definitiva"151, o la persona es absurda. Pero si la realidad superior, la personal, no puede carecer de sentido, hay que buscar de qué persona se es réplica, lo cual comporta un "auto-transcendimiento intelectual"152. En suma, el tema del conocer personal humano sólo puede ser personal, pero se trata de una persona tal que le manifieste quién es como persona, y eso, sólo Dios, porque sólo él sabe qué verdad, sentido, conocer o persona somos, ya que él nos ha creado. Que somos creados se muestra porque no somos idénticos, mientras que Dios es la identidad. La apertura del conocer personal es, pues, trascendente ${ }^{153}$, pero la trascendencia a la que se abre -"Dios transciende de manera inicial a todo hombre"154- no se desentiende de la búsqueda, orientación, destinación de todo conocer personal humano, sino que le sale al encuentro. La persona humana se convierte a una persona divina, y ésta, al aceptar la humana, la eleva sobrenaturalmente a su propio y lúcido ámbito irrestricto, asunto que supera por completo la actividad del ser personal humano; se trata, pues, de una "donación divina enteramente gratuita"155.

\footnotetext{
148 Ibid., p. 304.

149 Cfr. Ibid., p. 309.

150 Cfr. Ibid., p. 310.

151 Cfr. Ibid., p. 311.

152 Cfr. Ibid., p. 313.

153 Cfr. Ibid., p. 367 ss.

154 Ibid., p. 370.

155 Ibid., p. 381.
} 
Por su parte, en su escrito "Leonardo Polo on the act of being: precedents and a proposal for developement"156, Salvador Piá, tras distinguir la metafísica y la antropología por sus respectivos trascendentales, alude -siguiendo a Polo- al 'intelecto personal' (entendimiento agente) como un trascendental personal vinculado al amar personal ${ }^{157}$. Tras la sumaria exposición de los trascendentales personales, ofrece su propia propuesta consistente en sostener que la distinción entre los distintos actos de ser reales descubiertos por Polo (el del universo, el humano y el divino son distinciones trascendentales, pero que no son las distinciones reales superiores, pues, por encima de ellas están las distinciones "intra-trascendentales"158, a saber, las internas a los actos de ser personales; o sea, los actos de ser (cósmico, humano, angélico y divino) se distinguen internamente. Los anteriormente aludidos 'trascendentales personales' humanos, entre los cuales está el intelecto personal son los que, precisamente por ser distintos al acto de ser del universo físico, posibilitan la apertura interior o intimidad ${ }^{159}$, pero, a distinción de esos trascendentales en el ser divino, son jerárquicamente distintos.

\section{Conclusiones}

De entre el cúmulo de pensadores que han comentado el pasaje aristotélico sobre el intelecto agente a lo largo de la historia de la filosofía (son millares), hasta el momento hemos tenido acceso a las obras de más de un centenar, y hemos podido investigar pormenorizadamente este tema en sus escritos. De entre todos esos autores, los que mejor han entendido -a nuestro entender- el descubrimiento aristotélico, y que guardan posiciones más afines a la excepcional de San Alberto Magno, son los que lo vinculan al acto de ser humano, y esos son los siguientes pensadores españoles, tan agudos como desconocidos:

1. Francisco Canals. En el resumen de su primer trabajo "El 'lumen intellectus agentis"”-de horma tomista-, sostiene que para aclarar el sentido de la luz del inte-

\footnotetext{
156 Piá Tarazona, S.: "Leonardo Polo on the act of being: precedents and a proposal for developement", Rivista di Filosofia Neoscolastica, 2, 2003, pp. 169-97.

157 "This transcendental openness of the human esse is also a cognitive and loving openness, because intellection and love are modes which are proper to personal openness... No doubt these Polian comparisons and conversions within the human esse (co-existence) of personal freedom, the personal intellect and personal love will sound novel and surprising... But... Leonardo Polo studies personal freedom, personal intelligence and personal love as purely human perfections contained within the personal esse". Ibid., p. 192.

158 Ibid., p. 194.

159 "These intra-transcendentals distinctions are intimate to esse, and not merely transcendentals distinctions". Ibid., p. 194.
} 
lecto agente hay que conjugar dos tesis que toma de sendos comentadores tomistas: "Intellectio est actus ipsius intelligibilis" (Juan de Sto. Tomás), e "Intelligere nihil aliud est quam quoddam esse" (Cayetano). Niega que el intelecto agente sea una potencia y un acto como operación inmanente, y afirma que hay que vincularlo al orden del 'esse': "al 'esse', que, 'en cuanto es del alma, no depende del cuerpo, le compete la luz inteligible que llamamos 'entendimiento agente"”. Pero esa vinculación no denota explícitamente una equivalencia, que tampoco es manifiesta en su segundo trabajo: Sobre la esencia del conocimiento.

2. Leonardo Polo. Hace equivaler explícitamente el intellectus agens al acto de ser personal humano, siendo uno -junto con la coexistencia libre y el amar personal- de los por él llamados 'trascendentales personales', perfecciones puras no de orden 'metafísico' (como el ser, la verdad y el bien), sino 'antropológico' (trascendentales que prolongan los metafísicos). El intelecto agente es la raíz de todo conocer humano, pues de él nacen los hábitos innatos, la inteligencia, sus actos y hábitos adquiridos. A diferencia de esos otros conocimientos humanos menores, cuya luz es iluminante, la del intelecto agente es transparente, y su tema es el ser divino. Está separado de lo inteligido, es sin mezcla de órgano corpóreo; es, a diferencia de la inteligencia (o intelecto posible), impasible; está siempre en acto, aunque su actividad sea inconsciente, y es por eso superior al posible. Polo prolonga el hallazgo aristotélico del intelecto agente en la línea del actus essendi hominis, pero deja sin explorar algunas notas que Aristóteles le atribuyó, explicación que sería deseable.

3. Los discípulos de ambos filósofos. A) El discípulo de Canals, Juan García del Muro, afirma que intelecto agente participa del acto de ser del hombre. Como su maestro, vincula el intelecto agente al esse hominis, pero añade -tras afirmar que en el alma cabe distinguir lo potencial de lo activo-, que si lo potencial pertenece a la esencia del alma, "el ser del alma es el acto de los mismos inteligibles", un conocer que no es otra cosa que ser, un conocimiento permanente. Con todo, identifica este conocer con el conocer que el alma tiene de sí misma, asunto que no es correcto, pues la criatura es dual también en su dimensión cognoscitiva.

B) Por otro lado, en los discípulos de Polo observamos que, para Ignacio Falgueras el intelecto agente, al que llama 'entender personal', es un trascendental antropológico o 'incondicional', frente a los metafísicos o 'condicionales'. "Entender es la riqueza del ser" personal, dice. Por su parte, Ricardo Yepes, pese a referir que el intelecto agente es un trascendental según la filosofía de L. Polo, él no lo expone como tal en sus obras de corte personal. Por el contrario, para Juan A. García, este intelecto, al que él llama 'coagente' es un trascendental personal, un método, que tiene como tema a Dios, pero que no lo tiene como 'inteligible', sino como 'inteligente' del ser humano; de ahí la denominación de 'intelecto coagente'. En la misma línea, José Ignacio Murillo afirma que "la persona es acto de entender" distinto, por superior, a los actos cognoscitivos del su razón; insinúa, por tanto, 
que el intelecto agente no es un conocer de orden predicamental sino trascendental. Por último, para Salvador Piá Tarazona el intelecto agente, al que llama 'intelecto personal', es una perfección personal 'intra-trascendental', cuya luz no es iluminante sino transparente. Su tema es Dios en tanto que, tras el "auto-transcendimiento intelectual", en él busca el "reconocimiento interpersonal", que no encuentra en sí ni en los demás.

Es de esperar que esta exposición resumida y comentada de la más aguda versión hermenéutica del intelecto agente según sus escasos representantes sea fructífera de cara a la futura investigación del superior hallazgo aristotélico referido al hombre.

Juan Fernando Sellés

Universidad de Navarra

jfselles@unav.es 